\title{
El Real Madrid, ¿"equipo de España"? Fútbol e identidades durante el franquismo
}

\author{
Eduardo GonZÁlez CALLEJA \\ Universidad Carlos III de Madrid \\ edgcalle@hum.uc3m.es
}

Recibido: 01-10-2013

Aceptado: 04-06-2014

\section{Resumen:}

En los años 50 y 60 del siglo pasado, el Real Madrid C. de F. se convirtió en el heraldo deportivo del "milagro español", generando en España y el extranjero una oleada de admiración que, oportunamente capitalizada por el régimen franquista, convirtió al club en uno de los más eficaces difusores del "nacionalismo banal" que la dictadura quiso inculcar en la población, especialmente la emigrada. Esta imagen del Real Madrid como entidad deportiva de éxito internacional sirve de excusa para hacer una reflexión sobre las relaciones que se suelen establecer entre el deporte y el poder político, especialmente en el vidrioso tema de las identidades nacionales.

Palabras clave: deporte, franquismo, fútbol, identidad nacional, Real Madrid C. de F. 


\title{
Real Madrid, "team of Spain"? Football and identities during the francoism
}

\begin{abstract}
:
In the 50s and $60 \mathrm{~s}$ of the last century, Real Madrid Club of Football became the sportive herald of "Spanish miracle", generating in Spain and abroad a wave of admiration that was promptly capitalized by the Franco regime. During the Francoism, the club became one of the most effective disseminators of "banal nationalism" that the dictatorship would inculcate in the population, especially the emigrants abroad. This image of Real Madrid as an internationally successful sport entity allows us to reflect on the relationships that are established between sport and political power, especially in the elusive theme of national identities.
\end{abstract}

Keywords: football, francoism, national identity, Real Madrid Football Club, sports

\section{Referencia normalizada}

González Calleja, E. (2014). "El Real Madrid, ¿"equipo de españa"? Fútbol e identidades durante el franquismo". Politica y Sociedad, Vol 51, Núm. 2: 275-296

Sumario: 1.El "nacionalismo banal" en el deporte. 2.Los años heroicos y la forja de una identidad supralocal (1902-1936). 3.La "travesía del desierto" en el apogeo del nacionalismo totalitario (19391943). 4.El gran "salto adelante" (1944-1954). 5.La otra Casa Blanca: el Real Madrid como agente del nacionalismo español de exportación (1955-1960). 6.El lento declive y el ocaso del mito referencial madridista (1961-1978). 7.Conclusión: el Real Madrid, ¿equipo de España? 
El Real Madrid Club de Fútbol ejemplifica como pocas entidades deportivas españolas el grado de incidencia que ha tenido la política sobre la evolución de una institución que, con el paso de los años, se ha convertido en una auténtica organización empresarial con ramificaciones e intereses en medio mundo. La naturaleza no siempre idílica de sus relaciones con la dictadura del general Franco, que en su fase de plenitud presidió la etapa de los grandes éxitos internacionales del club, ayuda a entender la naturaleza equívoca de las relaciones que se suelen establecer entre el deporte y el poder político, especialmente en el vidrioso tema de las identidades nacionales.

\section{El "nacionalismo banal" en el deporte}

Especialmente en los años cincuenta y sesenta, el Real Madrid se convirtió en el heraldo deportivo del "milagro español", generando en España y el extranjero una oleada de admiración que, capitalizada por el régimen, convirtió al club en uno de los vehículos difusores del "nacionalismo banal" que, según Michael Billig, orienta las percepciones cotidianas de la población y hace aparecer como natural la identificación entre una lengua, una cultura, un territorio y una comunidad política (Billig, 1995). El ritual deportivo, que actúa como el sustitutivo laico de las aspiraciones religiosas, es uno de los modos más ilusorios y accesibles de comunión colectiva. En efecto, el deporte tiene todos los ingredientes necesarios para ser interpretado como una religión civil: ritual público, liturgia cívica o política y devoción popular encaminada a conferir poder y a reforzar la identidad de una colectividad (García Ferrando, Puig Barata y Lagardera Otero [comps.], 1998: 19). Como conjunto de representaciones colectivas, el deporte entendido como religión laica ha logrado construir un sistema de mitos coherente y sólidamente estructurado: la creencia en el progreso lineal e indefinido, el mito del superhombre, la exaltación de la disciplina, el heroísmo cuasi-militar, la comunión de valores e intereses entre el deportista y la afición, etc.

El potencial simbólico del deporte y su enorme capacidad de reforzamiento de la identidad colectiva facilitó su integración temprana en la liturgia nacional. Pocas manifestaciones públicas se han mostrado tan útiles en el fomento de la mística nacionalista como la actividad deportiva, desde su inicial pretensión formativa a su actual faceta competitiva. A inicios del siglo XIX se desarrollaron las escuelas gimnásticas nacionales como base histórico-cultural de la educación física. La idea motriz era la preocupación patriótico-militarista: se trataba de formar soldados fuertes y ágiles, capaces de defender a la patria. De ahí que la gimnasia fuera controlada desde el primer momento por la institución militar (más tarde pasaría al sistema educativo civil), y fomentada por todos los movimientos nacionalistas en sus campañas de "nacionalización de masas" (Mosse, 1975: 185-197). El deporte ha permitido afirmar una conciencia nacional oprimida por parte de elementos extranjeros, o bien superar las causas habituales de división interétnica. Incluso ha contribuido a revitalizar nacionalidades sin Estado más o menos depauperadas. El empleo 
de la gimnasia, la educación física y el deporte como difusores del espíritu patriótico y de la disciplina civil fue también empleado por los movimientos autoritarios y totalitarios de entreguerras, incluida la Dictadura de Primo de Rivera (González Calleja y Rey Reguillo, 1995: 190-195 y Quiroga Fernández de Soto, 2004) ${ }^{1}$. No tiene nada de sorprendente que los militares monopolizaran las actividades gimnásticas y deportivas en esos años, ya que la educación física se empleó como base de la educación premilitar de la juventud. Incluso en la Unión Soviética, tras un período de fuerte crítica al deporte entre 1917 y 1922, se llevó a cabo una reorganización que integró a los clubes en los sindicatos, mientras que las federaciones deportivas se encargaron de garantizar el control de las reglas. En 1931, la organización juvenil comunista Komsomol inició un programa de práctica deportiva de masas por edades y con un objetivo de premovilización patriótica dirigida al esfuerzo bélico (Pierre Laguillaume, "Para una crítica fundamental del deporte", en "Partisans", 1978: 48). En Francia, el modelo deportivo estaba más basado en el movimiento renovador nacionalista que en el modelo educativo inglés. Entre 1872 y 1914 proliferaron sociedades de preparación física y militar en todo el país con el objeto explícito de la revancha (en 1873 se creó la Union des Sociétés de Gymnastiques de France) en un contexto cultural fuertemente chauvinista. También se ha afirmado con frecuencia que las bases morales del Imperio Británico se sentaron en las duras competiciones deportivas entre colleges.

$\mathrm{Al}$ igual que la gimnasia, el deporte de contacto con la naturaleza, vinculado con el culto telúrico a la patria, ha sido un eficaz método reproductor de cultura política en algunos movimientos nacionalistas españoles, como sucedió con los mendigoizales (montañeros) del Partido Nacionalista Vasco y con los clubes excursionistas catalanes de fin de siglo, inspirados en el "montañismo de combate" practicado por la juventud nacionalista mazziniana desde mediados del siglo XIX.

La potencialidad nacionalizadora del deporte de masas no ha cesado de aumentar. En la actualidad, asistimos a la transformación de la actividad deportiva internacional en una auténtica "guerra total" desarmada, ya que el deporte permite canalizar la emoción de las masas por la vía nacionalista agresiva (Vinnai, 1970: 81). Los atletas estatales se han convertido en "soldados del deporte" encargados de una misión en el extranjero: la defensa de los colores nacionales. En realidad, la parafernalia nacionalista siempre ha acompañado a manifestaciones deportivas como los Juegos Olímpicos, que no se han utilizado tanto para promover el juego limpio, la

${ }^{1}$ En 1919, el Ministerio de la Guerra fundó en Toledo la Escuela Central de Gimnasia, y desde el año 1924 fueron formados en ella profesores civiles para la enseñanza de las escuelas. En 1925, Primo de Rivera nombró una comisión encargada de diseñar un plan nacional de formación física y premilitar de la juventud. A mediados de 1927 vieron la luz unas "Bases para el desarrollo en España de la Educación ciudadana, física y premilitar", que establecía la educación física hasta los 18 años. A inicios de 1929, estas labores de pedagogía patriótica a través de la gimnasia fueron asignadas a un Comité Nacional de Educación Física bajo control castrense. 
paz y la comprensión mutua en el contexto internacional, como para manifestar el orgullo y los intereses nacionales.

En resumen, desde mediados del siglo XIX la actividad deportiva ha actuado como parte constitutiva de la liturgia nacional (no hay sino que contemplar el éxito político alcanzado por el partido de Silvio Berlusconi, Forza Italia, bautizado con el grito de guerra de los tifosi de la selección de fútbol transalpina), pero su enorme capacidad de proyección pública ha determinado su manipulación por parte del Estado como instrumento de prestigio en la escena internacional.

Aunque el desarrollo imparable del fútbol-espectáculo se puede contemplar como una de las formas más tempranas de globalización cultural (Armstrong y Giulianotti, 1999: 4), este deporte ofrece un terreno privilegiado para la afirmación de identidades colectivas y de los antagonismos locales, regionales o nacionales. El fútbol plantea cuestiones sociales y psicológicas básicas para la sociedad contemporánea, como la cuestión de las identidades colectivas y su relación con la alteridad. No cabe duda de que el "deporte rey" sigue siendo uno de uno de los vectores más fuertes de identidad nacional, hasta el extremo de que los estilos y tácticas de juego (la furia española, el rigor alemán, la creatividad brasileña, la marrullería italiana, la determinación inglesa...) alimentan o confirman los estereotipos de los que se nutren nuestros imaginarios colectivos. Si el fundador de la FIFA, Jules Rimet, veía en el fútbol un instrumento al servicio de la aproximación de los pueblos, competiciones como la Copa del Mundo se plantearon desde el primer momento como una confrontación entre estados nacionales sometida a reglas precisas de espacio, tiempo y procedimiento. Cada confrontación facilita a los espectadores un apoyo a la simbolización de una de las facetas (local, profesional, regional) de su identidad en relación con las de los rivales más o menos próximos. La identificación con un club no es percibida o concebida por los seguidores como el simple signo arbitrario de la pertenencia común, sino como el símbolo motivado de un modo específico de existencia colectiva, que encarna el estilo de juego del equipo que no corresponde necesariamente con la práctica de los jugadores, sino a la imagen estereotipada que una colectividad de hace de ella misma (Bromberger, 1998: 59 y 77). Por ejemplo, la furia leonina del Athletic de Bilbao se trasladó a la selección española de fútbol, repleta de jugadores vascos, durante los Juegos Olímpicos de Amberes de 1920. En el caso que nos ocupa, virtuosidad, seriedad y precisión se identifican en la cultura del madridismo con "señorío", además de con fair play. La composición del equipo también ofrece una metáfora de esa identidad colectiva: sin dejar de hacer exhibición de españolismo, en el Real Madrid, el ius solis ha primado sobre el ius sanguinis propio de los equipos vascos, que hasta épocas recientes mantuvieron rigurosos criterios étnicos para la formación y el fichaje de sus jugadores. No hay problema en aceptar a futbolistas extranjeros o nacionales de otras regiones en una ciudad de aluvión como Madrid, siempre que éstos cumplan las reglas no escritas del clubciudad, entre las cuales figuran el agradecimiento a la hospitalidad ofrecida y el respeto a los símbolos locales, regionales y nacionales, sin especial distinción jerárquica entre ellos. Con todo, la relación del Real Madrid con su ámbito territorial más inmediato ha sufrido importantes variaciones, desde su imagen inicial de 
club capitalino por excelencia, en un virtual monopolio que duró más de cuarenta años, hasta el momento actual, en que sufre la competencia de otros clubes con arraigo en otras esferas sociales, barrios o localidades periféricas, como el Atlético de Madrid, el Rayo Vallecano o el Getafe.

A veces, la opción político-social no se expresa de forma consciente, sino que viene definida por la autodefinición de los rivales. En el caso del Real Madrid, ese "señorío" de contornos fuertemente elitistas (perfectamente expresado en la composición y el comportamiento social de las juntas directivas) queda confrontado con el popularismo, el desenfado y la mística de la derrota (en una autoinmolación casi religiosa) que cultiva el rival local Atlético de Madrid. Desde un punto de vista más político, la identidad monárquica y españolista del club se puede rastrear, como veremos, desde su fundación, pero se ha ido modulando en función de los distintos regímenes que se han venido sucediendo en España desde 1902. Pero su españolismo se ha definido con mucha frecuencia en relación con los rivales lejanos tanto social como geográficamente, en concreto los equipos vascos y el Fútbol Club Barcelona, heraldos tempranos de los nacionalismos periféricos. Resulta llamativo que la hegemonía de los equipos vascos en la década de los ochenta y la del Barça en los noventa e inicios del siglo XXI generase en el Real Madrid un cambio desde un nacionalismo español "constructivo", aglutinador y "de exportación" basado en sus triunfos internacionales a un nacionalismo reactivo y excluyente, centrado en la denigración de las identidades de los adversarios directos y transmitido por el sector más extremista de la afición: los Ultras Sur, de contornos subculturales neofascistas.

\section{Los años heroicos y la forja de una identidad supralocal (1902-1936)}

El origen del Madrid Foot-ball Club es esencialmente mesocrático. Entre sus primeros socios se contaban comerciantes, pequeños industriales y funcionarios civiles y militares. Desde su origen, el club parece estar imbuido de cierto sentimiento patriótico español. La misma idea de organizar en Madrid una competición nacional, germen del campeonato oficial de España, con ocasión de la entronización de Alfonso XIII, parece abonar esta hipótesis. Otra decisión del club, adoptada igualmente en los primeros días de su existencia, viene a reforzar la hipótesis de una temprana nacionalización simbólica: el artículo 18 de sus estatutos, que llevan la fecha del 18 de abril de 1902, detallaba las distintas piezas que componían el atuendo oficial, a tenor del tipo de competición en el que intervinieran:

"El uniforme reglamentario será para los partidos ordinarios pantalón azul oscuro, corto y recto, blusa blanca y medias oscuras, y para los partidos extraordinarios será pantalón y blusa blancos, medias negras con vueltas y cinturón con los colores nacionales, completando este uniforme un casquete azul oscuro".

Quizás influyó en esta norma estatutaria la presencia de un militar entre los fundadores del club, el coruñés Adolfo Meléndez. La disposición fue puesta en práctica: examinando la prensa gráfica de la época, se observa que el uso del cinturón apare- 
ce regularmente hasta 1915. Resultaba previsible que tal indumentaria y el hecho de representar a la capital del Estado en las primeras competiciones deportivas generaran los primeros roces con los nacionalismos periféricos en el ambiente de agitación de la Gran Guerra. La épica semifinal del Campeonato de España celebrada el 16 y 23 de marzo de 1916 contra el F.C. Barcelona, que hubo de resolverse en otros dos dramáticos encuentros de desempate celebrados el 25 y 26 de marzo, es el precedente de una rivalidad que aún hoy perdura. El último gol del cuarto encuentro, marcado por el madridista Aranguren, fue agriamente protestado por los azulgrana, que abandonaron el terreno de juego en señal de protesta (Melcón 1950: 30-31 y González, 1977: 177-179). La final, celebrada en Barcelona el 7 de mayo de 1916 en un ambiente hostil por el recuerdo de los incidentes producidos en la anterior eliminatoria, fue un paseo militar para un Athletic de Bilbao muy superior a su exhausto contrincante, que perdió por 4-0. El 12 de mayo de 1918 se perdió en el viejo campo del Athletic madrileño en O'Donnell la final del Campeonato de España frente al Real Unión de Irún por 2-0. Manuel Rosón contaba que "Santiago Bernabeu, Machimbarrena y Manolo Posada, tenían la consigna de gritar '¡Viva España!' cada vez que el Madrid marcase un goal. Pero, desgraciadamente, aquellos vivas quedaron inéditos" (Rosón, 1940: 28).

A la par que se hace gala de un pueril españolismo, en estos años iniciales se observa una voluntad temprana de proyección internacional: el 23 de octubre de 1905, con motivo de la visita a Madrid del presidente de la República de Francia, en visita de Estado, el club blanco preparó un partido de fútbol con el Gallia Sport de París, campeón de Francia. El evento supuso el comienzo de una proyección internacional que reforzó el papel del club como representante cualificado del deporte español en el extranjero. El Madrid, que contribuyó decisivamente a la fundación de la Federación de Clubs de Foot-Ball el 14 de octubre de 1909, obtuvo el título de Real Club el 29 de junio de 1920, lo que no implicaba solamente el añadir una corona al escudo de la entidad, sino mantener desde entonces una relación privilegiada con el monarca y su familia: Alfonso XIII fue nombrado presidente de honor, y sus hijos (y nietos) serían huéspedes asiduos de una institución deportiva que lo que tras reforzar su identificación con uno de los puntales del nacionalismo popular español como era la Monarquía, pronto traspasó las fronteras de lo local.

El Real Madrid fue el primer equipo español en aventurarse, en 1925, a cruzar el Canal de la Mancha y enfrentarse, en sus propios campos, a equipos ingleses, con el propósito de doctorarse en el país inventor del foot-ball. Dos años más tarde cruzó el Atlántico, para una gira de casi cuatro meses, que les lleva de Argentina a los Estados Unidos, pasando por Uruguay, Chile, Perú, Cuba, y México. Al regreso de la excursión, en el mes de octubre, la revista deportiva Gran Vida mantuvo una entrevista con Santiago Bernabéu, jefe de la expedición. Algunas de sus respuestas dejan entrever que los objetivos del viaje no fueron sólo deportivos y económicos, sino también patrióticos. A una pregunta del entrevistador sobre los resultados económicos, el directivo del Madrid respondía:

"Bueno. A diferencia de otras giras que hicieron los equipos de allá, nuestro afán era puramente deportivo. Hemos cubierto gastos, hemos hecho propaganda espa- 
ñolista, ¡con qué santo tesón todos!, y como al Club no le ha costado un céntimo, aunque nada haya ganado tampoco, nos damos por muy satisfechos".

A otra pregunta del periodista, donde se interesaba por la impresión que habían dejado entre los emigrantes españoles, Bernabéu expresaba su enorme satisfacción por el entusiasmo despertado entre los compatriotas de allende el Océano:

"Excelente, y eso es lo que más nos enorgullece. El resultado deportivo, que era esperado con enorme temor, ha proporcionado a los nuestros las satisfacciones más legítimas a que podían aspirar. Por eso estamos tan satisfechos de haber jugado y ganado algunos partidos de fútbol en América" (Gran Vida, octubre 1927).

Esta va a ser uno de los quehaceres perseguidos con mayor insistencia por el Real Madrid desde entonces: actuar como instrumento oficioso de nacionalización sobre unas comunidades de emigrantes desasistidas por la tradicional inacción del Estado liberal, que optaban por estructurarse en colectividades regionales (cada vez más penetradas por los nacionalismos periféricos) o perdían su identidad de forma acelerada, asumiendo los derechos y deberes de ciudadanía de los países de acogida. La cercanía a los valores patrióticos de la España oficial, y la conversión del club en una potente entidad deportiva de creciente proyección allende las fronteras, fueron circunstancias que permitieron que durante los años de la Dictadura de Primo de Rivera (1923-30) el Real Madrid se aproximase a los círculos financieros y empresariales, y a los ambientes elitistas de la sociedad madrileña, que patrocinaron la inauguración del primer estadio de Chamartín en mayo de 1924 como escenario para un deporte que se convertía de forma acelerada en un gran espectáculo de masas.

Fue entonces cuando la entidad abordó su primer gran cambio organizativo. Hasta mediados de los años veinte había prevalecido el modelo amateur puro, gestionado por la elite fundacional, pero el profesionalismo de los futbolistas y la multiplicación del número de socios obligaron a partir de esa época a una adaptación hacia un modelo híbrido semiprofesional que resultó enormemente conflictiva, como lo atestigua la rápida sucesión de presidentes (cinco) y de Juntas Directivas (seis) en la década de 1926-1936. En junio de 1926, la asamblea de la Real Federación Española de Fútbol (RFEF) implantó oficialmente el profesionalismo, generando una serie de exigencias económicas que los clubes modestos cada vez tenían más dificultad en cubrir con la participación en el único título importante del calendario futbolístico: la Copa de España. Fue entonces cuando, tras veinte meses de arduas negociaciones, se puso en marcha el Torneo Nacional de Liga a fines de 1928 (Martialay, 1996). La nueva competición, que sin duda reforzó la cohesión simbólica entre las regiones, brindó al Real Madrid una incomparable capacidad de irradiación e influencia a nivel nacional.

Con la proclamación de la Segunda República en abril de 1931, el Madrid perdió el título de "Real", pero de la mano de los presidentes Luis Usera Bugallal y Rafael Sánchez-Guerra (secretario general de la Presidencia de la República) siguió manteniendo relaciones privilegiadas con el poder político y vivió su segunda "edad de oro" 
con la obtención de los títulos de Liga de 1931-1932 y 1932-1933 y de las Copas de España de 1934 y 1936. El estallido de la guerra civil cortó en seco tan prometedora trayectoria. Sometido en agosto de 1936 a un proceso de incautación por parte de la Federación Deportiva Obrera vinculada al Frente Popular, el Madrid trató de sobrevivir durante el conflicto infiltrando algunos de sus directivos en el Comité de Incautación para preservar su patrimonio, y solicitando su incorporación al campeonato de fútbol catalán, pero el veto interpuesto por el F.C. Barcelona frustró este último recurso de supervivencia y aceleró la descomposición del equipo madridista en el otoño de 1936 (García Candau, 1996: 49 y Martialay y Salazar, 1997: 121-124).

\section{La "travesía del desierto" en el apogeo del nacionalismo totalitario (1939- 1943)}

El régimen franquista vencedor en la guerra civil privilegió el deporte como mecanismo de integración nacional, como instrumento de socialización política para los jóvenes y como herramienta de propaganda ideológica. El deporte se transformó en "cuestión de Estado", y en consecuencia los organismos competentes, sobre todo el Ejército y el partido único Falange Española Tradicionalista (FET), se vieron legitimados para interferir en su organización y exigir a las entidades deportivas una adhesión explícita a la política del régimen. El control absoluto de las actividades deportivas se realizó desde fines de 1938 a través del Consejo Nacional de Deportes, y desde febrero de 1941 por medio de su heredera la Delegación Nacional de Deportes (DND), directamente vinculada a FET. El predominio castrense resultó especialmente notorio en el fútbol. Desde el verano de 1936 funcionó en San Sebastián una oficina federativa oficiosa, dirigida por el teniente coronel Julián Troncoso Sagredo, que se autoproclamó Federación Nacional de España el 17 de octubre de 1937, y un mes más tarde logró, gracias a los buenos oficios de Jules Rimet, ser reconocida por la FIFA como la legítima depositaria de la representación española en los foros futbolísticos internacionales. Como en el resto de las instancias oficiales, la Federación nombró comités depuradores para sancionar a jugadores, entrenadores y árbitros que hubiesen mostrado su lealtad a la República. Troncoso advirtió además que las federaciones y los clubes de fútbol habían dejado de existir como entes autónomos, y exigió a los futbolistas virtudes análogas a las de un soldado. Era también un acérrimo enemigo del profesionalismo, que reputaba como absolutamente incompatible con la función cívico-política del deporte en el "Nuevo Estado".

El "Año de la Victoria" fue, sin duda, el más duro de la historia del Madrid: sin equipo, con el estadio en ruinas tras su transformación en campo de prisioneros, la sede social bombardeada, gran parte de los trofeos y del archivo desaparecidos, y con la estructura societaria dislocada, el reglamento en suspenso y la plantilla sometida a un meticuloso proceso de depuración, muchos pensaron que había llegado la hora de la clausura definitiva. La continuidad del club quedó al arbitrio de una Junta de Reconstrucción formada por los antiguos presidentes de la entidad, 
encabezados por el general Adolfo Meléndez. Este logró resistir las presiones de sus camaradas de armas para que el Madrid (que no recuperó su apelativo de "Real" hasta 1941) quedase absorbido en el equipo de la Aviación Nacional, que poco después daría lugar al Atlético de Madrid. Con ello se hubiese consumado la "Unificación" de los grandes equipos madrileños en una entidad de acusado tono militarista e impregnada de un nacionalismo de contornos totalitarios que casaba mal con la tradición conservadora y accidentalista del Madrid.

El club se salvó in extremis de la absorción, pero su actividad societaria quedó reducida a mínimos. En ese contexto de crisis, el Real Madrid purgó su identificación involuntaria con la capital de la República con un obligado alejamiento de los centros oficiales de decisión política y deportiva. En septiembre de 1942, la Junta Directiva del Real Madrid hubo de legalizar unos estatutos donde las instancias rectoras del club pasaron a ser elegidas directamente por la DND (Estatutos del "Real Madrid Club de Fútbol" [1-9-1942], en ARM, caja 119, carp. 5), aunque estas disposiciones fueron sustituidas en 1948 por un sistema de representación indirecta, en el que una Asamblea de compromisarios proponía una terna para que la RFEF designara luego el candidato "idóneo" a presidente, quien elegiría a su vez a los vicepresidentes y directivos, no olvidando la cuota de al menos dos falangistas en la lista. La falta de representatividad de la RFEF fue protestada por el Real Madrid, que decidió en 1963 boicotear los plenos y continuó sin asistir a los mismos hasta la caída del Delegado Nacional de Deportes, el falangista José Antonio Elola Olaso, en 1967. Con semejantes recortes en los derechos societarios, el interés de los afiliados en la gestión del club sufrió una merma evidente. En la prolongada etapa presidencial de Santiago Bernabéu (19431978), las Asambleas Generales que debían refrendar cada cuatro años su continuidad al frente del club acabaron por transformarse en un fastidioso ritual donde la exhibición de los trofeos deportivos obtenidos como respaldo simbólico de la ejecutoria de la Directiva ahogaba cualquier tipo de crítica. No había lugar a ruegos ni a preguntas, y Bernabéu finalizaba la sesión con un discurso paternalista que era más bien una arenga, invariablemente acogido entre aplausos por los compromisarios enfervorizados.

Los años cuarenta fueron los más pobres, deportivamente hablando, de la historia del Real Madrid durante el franquismo. Bajo las presidencias del general Meléndez y de Antonio Santos-Peralba, los resultados no pasaron de discretos frente a los logros del Bilbao, el Barcelona o el Atlético de Madrid. A pesar de los triunfos coperos de 1946 y 1947, el equipo estuvo a punto de descender a Segunda División en las temporadas 1942-1943 y 1947-1948. Además, la intromisión de la política en las actividades futbolísticas le acarreó serios problemas, como el que se produjo a raíz del enfrentamiento con el F.C. Barcelona en las semifinales de la Copa del Generalísimo en junio de 1943. El mal comportamiento del público madridista en el partido de vuelta, que finalizó con un escandaloso 11-1 favorable a los "merengues", fue el detonante de una crisis de relaciones con las instancias oficiales del deporte franquista que desembocó en una cuantiosa multa, la derrota "forzada" del Real Madrid en la final jugada contra el club vasco Athletic Bilbao, la inhabilitación del joven periodista Juan Antonio Samaranch por la publicación de una crónica muy crítica sobre el encuentro y el cese forzado de las Juntas Directivas de ambos clubes. La llegada de 
Santiago Bernabéu a la Presidencia del Real Madrid en septiembre de 1943 fue una solución de compromiso entre la Directiva del Real Madrid, ahora "blindada" con militares (Bernabéu nombró presidente honorario del club al teniente general Eduardo Sáenz de Buruaga, gobernador militar de Madrid y amigo personal de Franco) y una Falange obsesionada con asumir el control totalitario del fútbol.

A mediados de los años cuarenta, el Real Madrid era un equipo con claras vinculaciones en las esferas del poder (especialmente el militar, en alza tras el declive de Falange a partir de 1942), pero sin grandes medios económicos, y relegado en el terreno deportivo ante un influyente sector político que apoyaba firmemente al Atlético de Madrid. En esa época el club ya no era santo y seña del deporte español, y fue gracias al apoyo de los socios como Bernabéu lo transformó en una poderosa maquinaria social y deportiva. Su proyecto institucional y deportivo abrió el camino de la época más gloriosa del Club, que en veinte años se transformó en la entidad más admirada y respetada del fútbol mundial, con 16 Ligas, 7 Copas del Generalísimo, 6 Copas de Europa y una Copa Intercontinental obtenidas a lo largo de su mandato. No puede decirse que fuera hombre del régimen franquista, en el sentido estricto de la palabra, pero tampoco que se sintiera incómodo en su seno, aunque sus relaciones con las rígidas estructuras deportivas fueron cada vez más tensas. Su proclamado apoliticismo encubría un talante profundamente conservador y una sutil preferencia por el principio monárquico. Paterfamilias indiscutible e imprescindible desde los años cincuenta, el día a día de la "política" del club quedó en manos de sus más estrechos colaboradores, sobre todo en las de Raimundo Saporta, un hábil gestor económico de origen franco-armenio-judío, que por veinte años encabezó las relaciones del club con la España oficial, especialmente con la Falange (Bahamonde Magro, 2002: 202-213; Martín Semprún, 1994 y García Candau, 2002; Escandell Bonet, González Calleja y Villacorta Baños [coords.], 2002: II, 598-599).

\section{El gran "salto adelante" (1944-1954)}

A la altura de 1943, el ambiente reinante en el Real Madrid era de pesimismo por la falta de aliento local y las continuas derrotas deportivas. Fue entonces cuando Bernabéu trató de sortear la crisis interna con la presentación de un proyecto que muchos tildaron de irreal y megalómano: la construcción del estadio de mayor capacidad de Europa, adaptado a previsible multiplicación de los adeptos al "deporte rey" en la posguerra. La iniciativa resultó un rotundo éxito: la masa social o los simples inversionistas suscribieron las obligaciones con rapidez, y el aumento de las recaudaciones gracias al mayor aforo del nuevo estadio sirvió para pagar la deuda.

La consolidación deportiva del Real Madrid como el mejor club del fútbol español estuvo acompañada de su afianzamiento económico. A inicios de los 50 , la entidad blanca era ya el mayor contribuyente deportivo de España. Logrado el sueño del nuevo estadio (que fue inaugurado el 14 de diciembre de 1947, y que adoptó oficialmente el nombre de Santiago Bernabéu en enero de 1955), con la situación financiera estabilizada y una afluencia masiva de nuevos socios (42.000 en 1953), 
Bernabéu afrontó el reto de modelar un equipo acorde con la grandeza patrimonial recién adquirida. Llenar el estadio requería contar con los mejores jugadores del mundo, con lo que se dispararon los gastos en fichajes. La primera gran ocasión la brindó el torneo conmemorativo del Cincuentenario de la Entidad disputado en marzoabril de 1952 entre el anfitrión, el Norkoeping sueco y el Millonarios de Bogotá, en cuyas filas actuaba el que sería el mejor futbolista mundial de la década siguiente: el argentino Alfredo Di Stéfano. El rocambolesco fichaje de la "Saeta Rubia" por el club blanco en enero-septiembre de 1953, en detrimento de su eterno rival barcelonista, sigue haciendo correr ríos de tinta, y figura en el primer lugar de las polémicas extradeportivas del fútbol español, afianzando la leyenda del Real Madrid como "equipo del régimen" (Di Stéfano, 2000: 111-118; Escandell, González Calleja y Villacorta Baños [coords], 2002: I, 161-174; Fernández Santander, 1990: 52-53; García Candau, 1996: 174-181; González, 2002: 155-160; Martialay y Salazar, 1997: 326-346; Shaw, 1987 : 200-201; Sabartés, 1982: 36-42 y Burns Marañón, 1999: 208-214).

Conseguido el saneamiento económico y la paz societaria, el club dio el "gran salto adelante" en su proyección internacional. El punto de partida no era nada alentador. En la posguerra mundial, el Real Madrid disputó los primeros partidos internacionales con equipos de "países amigos" como Portugal o Argentina. En el verano de 1948, la DND solicitó instrucciones al Ministerio de Asuntos Exteriores sobre la conducta a seguir en partido internacionales. Hasta ese momento se había observado rigurosamente "el acuerdo prohibitivo de concertar partidos de fútbol con naciones que no guardan con España relaciones de franca amistad". Sin embargo, para que el aislamiento deportivo no se sumase al diplomático, la Delegación sugería la conveniencia de adoptar en lo sucesivo una solución intermedia:

"Evitar que el equipo nacional representativo de España jugase con los de países no amigos declarados, pero permitiendo los encuentros locales, o de Club con Club, así como también nuestra intervención en la Copa Latina por su carácter racial del que no estamos apartados" (AMAE, leg. R-2586, exp. 46).

El Ministerio de Asuntos Exteriores elaboró en julio de 1948 unas "Normas para la celebración de encuentros internacionales de fútbol", que prohibía celebración de "encuentros en los cuales exista un evidente riesgo de derrota para el conjunto nacional", y se establecía una autorización diplomática para los mismos. Como medida paliativa, la Federación Española de Fútbol fue requerida para procurar la participación de "los mejores equipos nacionales, asegurándose de que el rival extranjero es de categoría equivalente, y siempre en las mejores condiciones de eficacia y, previa, naturalmente, la consulta de rigor" (AMAE, leg. R-2586, exp. 46).

Con la relajación de las sanciones diplomáticas a partir de 1950, el Real Madrid volvió a atravesar el Atlántico en 1952 para disputar encuentros contra equipos de varios países iberoamericanos. En Bogotá, la colonia española organizó un banquete con asistencia de unas doscientas treinta personas de "todas las clases e ideologías", en medio de una cordialidad "sin precedentes". La prensa y la radio destacaron el comportamiento de los futbolistas, que dejaron una magnífica impresión, "por su corrección impecable, caballerosidad deportiva y patriotismo". La gira 
siguió cosechando éxitos similares en Caracas y La Habana (AMAE, legs. R-3701, exps. 140 y 141, y R-3702, carp. 42, y ARM, caja 48, carp. 2, y caja 125, carp. 1). La Federación Española de Fútbol trasladó su satisfacción al Presidente del club por "el éxito logrado, que sobrepasa el simple triunfo de un equipo para convertirse en un auténtico suceso español". El Ministerio de Asuntos Exteriores se hizo eco de los informes transmitidos por su representante diplomático en Bogotá, al considerar que la visita del Real Madrid había sido "muy favorable al buen nombre de España". El Jefe Nacional del Servicio Exterior de Falange tampoco se quedaba atrás, al expresar que "difícilmente en la historia deportiva de los equipos españoles se ha conseguido, como en este caso, levantar tal cantidad de admiración, simpatía y devociones" ("Felicitación del Ministerio de Asuntos Exteriores y la R.F.E. de Fútbol", BIRM, I, 27, septiembre 1952, p. 3 y "El Jefe Nacional del Servicio Exterior felicita a nuestro Club", BIRM, I, 31, enero 1953, p. 3). Fue el momento en que el Real Madrid comenzó a transformarse en el embajador oficioso de España (y su régimen político) en el extranjero. Desde mediados de los cincuenta, el Real Madrid se integró perfectamente en la red de influencias de un régimen que le contemplaba como la gran baza de promoción de cara al exterior, en el momento decisivo del final del régimen económico autárquico y en el comienzo de un proceso de estabilización que desembocaría en los años del desarrollismo. La asociación de los triunfos deportivos de un club con el prestigio de España, y de la nación con su sistema de gobierno, constituían un encadenamiento de premisas que los medios de comunicación controlados por ese mismo gobierno se encargaban de resaltar. El régimen político inició una política de acercamiento marcada por la mutua conveniencia: tras la conquista de la Copa Latina en París el 25 de junio de 1955, un Decreto de la Jefatura del Estado otorgó la Cruz del Yugo y las Flechas al equipo del Real Madrid por su primer gran éxito en el exterior.

Sin duda, ese año 1955 marcó un antes y un después en las relaciones entre el club y el régimen de Franco, aunque es preciso no considerar al franquismo o al Real Madrid como realidades monolíticas. Es indudable que uno de los factores tradicionales de sintonía con la Dictadura fueron las excelentes relaciones que el club siempre mantuvo con el estamento militar. En aquellos años era habitual encontrar algún alto mando castrense en las Juntas Directivas del Madrid ${ }^{2}$. La amistad personal de Bernabéu con el general Agustín Muñoz Grandes (jefe de la "División Azul" enviada al frente ruso en 1941, ministro del Ejército de 1951 a 1957 y vicepresidente del Gobierno de 1962 a 1967), a cuyas órdenes combatió en la 150 División durante la guerra civil, solucionó enojosos conflictos con otras personalidades del régimen.

${ }^{2}$ El general José María Troncoso fue vicepresidente en 1951; el general Benito Pico fue vocal en esa misma directiva, y vicepresidente en las dos siguientes; y el contraalmirante Fernando de Abárzuza fue directivo desde 1956 hasta 1962. Entre 1939 y 1978, el 12,5\% de los directivos del club eran militares. 
La aproximación entre el régimen y el Real Madrid se tradujo en una interlocución privilegiada con las altas instancias del Gobierno y del Estado. Hasta el inicio de los éxitos europeos, la documentación del Real Madrid sólo registra una audiencia con Franco, en 1952, para entregarle el Libro de Oro conmemorativo del cincuentenario de la entidad. Fue a partir de 1954 cuando se constata una mayor comunicación con el entorno protocolario y familiar del Generalísimo. Desde entonces, la presencia de Franco y de su esposa en el palco del estadio Bernabéu se hace habitual: unas veces, con ocasión de las demostraciones sindicales de la Fiesta del Trabajo (1 de mayo), que tuvieron por escenario el estadio Santiago Bernabéu desde 1957. Otras, con motivo de importantes eventos deportivos de la selección nacional o del propio club.

Sin embargo, este "luna de miel" con el régimen no se tradujo en una distensión con los niveles intermedios del aparato político encargado de la gestión deportiva. Las relaciones con los mandos superiores de Falange a través de la DND fueron siempre muy difíciles, aunque la correspondencia con las jerarquías intermedias fue muy fluida. Saporta actuaba como el interlocutor más cualificado con la tendencia "azul" del régimen y en su correspondencia privada aparece como más franquista y menos monárquico que el presidente. Sin duda la veta monárquica, de vieja tradición en el club, fue la más explotada, aunque siempre con discreción, sobre todo a partir de los años cincuenta. El Madrid mantuvo una relación constante con la familia real en el exilio, lo que generó algunas tensiones con la Dictadura: antes del debut en la Copa de Europa frente al Servette en Ginebra el 8 de septiembre de 1955, el equipo visitó en Lausanne a la ex-reina Victoria, a su hijo don Juan y a su nieto el infante don Juan Carlos. Estos últimos acudieron a ver el partido, que fue ampliamente destacado por la prensa franquista, aunque ésta mantuvo un significativo silencio sobre el gesto político previo (Di Stéfano, 2000: 174-175).

\section{La otra Casa Blanca: el Real Madrid como agente del nacionalismo español de exportación (1955-1960)}

El fichaje de Di Stéfano abrió el camino a una sucesión de triunfos nacionales (Ligas de 1953-54 a 1957-58) e internacionales (Copas Latinas de 1955 y 1956), pero el impulso definitivo vendría de la mano de una competición absolutamente renovadora: la Copa de Europa de Clubes Campeones de Liga. Bernabéu y Saporta participaron activamente en la iniciativa patrocinada por el diario deportivo L'Équipe en abril de 1955 con el beneplácito del embajador español en París, conde de Casa Rojas, y la intervención de los organismos deportivos falangistas, el aparato diplomático y el propio Gobierno franquista, que llegó a debatir las implicaciones políticas de la iniciativa madridista en un Consejo de Ministros (AMAE, leg. R4833, exp. 50).

En un momento en que el país apenas estaba saliendo del aislamiento internacional, el viaje del Real Madrid a la Yugoslavia del mariscal Tito para jugar la eliminatoria de cuartos de final frente al Partizan de Belgrado y la obtención el 13 
de mayo de 1956 de la primera Copa de Europa en el Parque de los Príncipes ante el Stade Reims supuso una fuerte conmoción mezclada con un sentimiento de orgullo nacional. El Real Madrid, que desde los años veinte había abogado por la reforma competitiva del fútbol europeo, se convirtió en la segunda mitad de la década de los cincuenta en un club reputado y respetado a nivel internacional, cuyos directivos eran apreciados por buena parte de las personas e instituciones que se movían en torno a este deporte. En ese contexto tan favorable, el estrechamiento de los lazos con el régimen franquista se efectuó con toda naturalidad. El inicio de las "glorias deportivas" madridistas coincidió con el momento en que el régimen de Franco dejaba de ser el paria político del mundo occidental gracias a la firma de los pactos militares con los Estados Unidos en septiembre de 1953.

El papel del Real Madrid como embajador extraordinario de España resultó extremadamente útil en esta coyuntura de profundos cambios en la política exterior, donde la proyección cultural hacia América Latina resultaba un campo prometedor en el contexto de la nueva política atlántica concertada con Washington. En los países donde existían colonias españolas importantes, la llegada del club blanco se convirtió en un acontecimiento excepcional, que era aprovechado por los cónsules y embajadores para reforzar su predicamento entre los emigrantes o limar asperezas con las asociaciones de exiliados. Las embajadas o legaciones diplomáticas organizaban siempre recepciones especiales con motivo de los viajes del equipo. A ellas solían asistir, además de los jugadores y directivos madridistas o de los equipos que jugaban contra ellos, un buen número de dirigentes y periodistas deportivos del país visitado, además de autoridades políticas locales y nacionales. Por ese conducto también se distribuían a veces las entradas para los partidos internacionales del equipo, y su intermediación era básica para lograr que los directivos madridistas aceptasen enviar uniformes u otros regalos del club para los equipos de fútbol formados por emigrantes en Europa, el norte de África o Latinoamérica.

Las colonias de emigrantes españoles en todo el mundo conocían y apreciaban los éxitos del Real Madrid. Les devolvían el orgullo de la pertenencia a su país. Cada vez que el equipo jugaba en los países donde se habían instalado procuraban acudir para verle actuar, o seguían los partidos a través de la televisión. Era un acto social que servía para la identificación de la colectividad. Sus triunfos eran celebrados como propios, como una demostración de lo que daba de sí el pueblo español, o como una modesta compensación frente a unas sociedades más opulentas que solían mirarles por encima del hombro.

Es cierto que el Real Madrid permitió voluntaria y conscientemente su utilización como embajador oficioso, sin provocar ninguna situación conflictiva ni renegar del régimen político español ni de sus dirigentes (Shaw, 1987: 44). Los directivos blancos siempre informaban al Ministerio de Asuntos Exteriores de sus compromisos internacionales, solicitaban su visto bueno antes de aceptarlos y remitían una valiosa información complementaria, especialmente de los países de bloque comunista, donde actuaron como interlocutor alternativo a los restringidos circuitos oficiales. No es de extrañar que Alfredo Sánchez Bella, ministro de Información y Turismo de 1969 a 1973, calificara al Real Madrid como "uno de los mejores 
instrumentos, acaso el mejor y mayor que en los últimos tiempos hemos tenido, para afirmar nuestra popularidad fuera de las fronteras" (AMAE, leg. R-8622, exp. 8), o que el ministro de Exteriores Fernando María Castiella dijera algunos años más tarde que "el Madrid ha constituido la mejor embajada que hemos enviado al extranjero" ("Banquete dedicado al Real Madrid", BIRM, IV, 128, enero 1961, pp. 9-11). El club era "todo un estilo de deportividad, y sabe pasear por el mundo con el máximo decoro el nombre de España. Sus jugadores se comportan como auténticos embajadores, al contribuir con sus actuaciones al prestigio de nuestra patria" (declaraciones a $A B C, 12-12-1968)$. El régimen comenzó a difundir la imagen de un equipo que se había convertido en la referencia del fútbol europeo y mundial. Una aureola de reconocimiento que también era apreciada y elogiada por los dirigentes políticos españoles, como el ministro secretario general del Movimiento, José Solís Ruiz:

"Habéis hecho mucho más que muchas embajadas desperdigadas por esos pueblos de Dios. Gente que nos odiaba ahora nos comprende, gracias a vosotros, porque rompisteis muchas murallas [...] Vuestras victorias constituyen un legítimo orgullo para todos los españoles, dentro y fuera de nuestra patria. Cuando os retiráis a los vestuarios, al final de cada encuentro, sabed que todos los españoles están con vosotros y os acompañan, orgullosos de vuestro triunfos, que tan alto dejan el pabellón español” (BIRM, vol. IV, n 112, noviembre 1959, p. 3).

No resulta extraño que, a comienzos de los años sesenta, la revista Fotos utilizara el titular "En los campos donde ha jugado el Madrid no se pone el sol" para ilustra un mapa donde se marcaban las ciudades que el equipo había visitado en sus diversos periplos internacionales (AMAE, leg. R-8622, exp. 6). El equipo recibía constantes proposiciones para desplazarse al extranjero, gracias, sobre todo, a sus éxitos en la Copa de Europa de fútbol y en otras competiciones internacionales, como el baloncesto. Esta tendencia se consolidó a partir de 1962 con la presencia de Manuel Fraga Iribarne en el Ministerio de Información y Turismo. Al tiempo que se vendía la "marca Madrid" se forjaban desde los medios oficiales y oficiosos del régimen otras figuras de la pretendida modernidad desarrollista como El Cordobés, Raphael, Marisol o Manolo Santana.

A inicios de los sesenta, el Real Madrid era, indiscutiblemente, el equipo más popular del mundo, como lo atestiguaba la publicación de libros en inglés sobre sus éxitos deportivos (Melcón y Smith [eds.), 1961). El reconocimiento de sus méritos trascendió con creces el estrecho marco diplomático en que se movía el régimen franquista. Éste supo situarse en la estela madridista para compensar su escasa proyección exterior. Si a ello le añadimos un panorama deportivo nacional cuyos resultados en las citas olímpicas solían ser bastante decepcionantes, puede comprenderse mejor la importancia que tuvo la aureola vencedora del Real Madrid. En torno a él se concentraron muchas expectativas, como el representante de un país que tenía pocos motivos para sentirse orgulloso más allá de sus fronteras. El diplomático Inocencio Arias, que fue director general del Real Madrid en la presidencia de Ramón Mendoza, llega a las siguientes conclusiones: 
"El inicio de la gesta europea blanca se produce en la época en que el Régimen de Franco estaba aún aislado internacionalmente; empezaba a dejar de ser, con la firma del acuerdo con los EE.UU, 'el paria político de Europa Occidental', según la expresión de Payne. Los embajadores extranjeros habían retornado a Madrid después de su marcha ordenada por Naciones Unidas, pero el Régimen no era presentable en la Europa democrática. La deslumbrante y repentina aureola madridista resultaba algo precioso para un Gobierno totalmente arrinconado en Occidente. España también había sido excluida del Plan Marshall que ayudaría a Europa a ponerse de pie después de la Guerra, y que contaba con unos magros resultados deportivos internacionales (sólo cuatro medallas a lo largo de seis Olimpiadas).

El Régimen se esforzó en explotar la fama del Madrid. De ahí a concluir que el Gobierno había concienzudamente ayudado al club y urdido entre bastidores una buena parte de sus victorias había sólo un paso, que los amantes de la teoría conspiratoria de la Historia y los también numerosos enemigos del Madrid franquearon rápida y ávidamente. Nació así la leyenda del Madrid creación y ‘equipo del régimen'. La teoría es una sandez. En los años en que el sistema franquista era más franquista (1940-1952), el Madrid no ganó ningún título liguero. Ni ayudas ni tramas. El club inventó y cimentó él solito (Di Stéfano, Gento, Bernabéu...) su sin par trayectoria europea. Creada ésta, el Régimen, ayuno de triunfos exteriores, se esforzó por montarse en el autobús del Madrid” (El Real Madrid, campeón de Europa, 1996: 367).

Esta "leyenda negra" del Real Madrid como "equipo del régimen", vinculado a un nacionalismo español trasnochado y excluyente, se desplegó en varias afirmaciones rotundas y polémicas: que Bernabéu era un franquista que trató de emular al Caudillo en su modo de dirigir del club; que la mayoría de los socios y afiliados eran franquistas; que el club alentó y se enorgulleció del apoyo personal de Franco y de sus ministros, que dominó la RFEF y se benefició de arbitrajes parciales, y que permitió conscientemente que se le usase para mejorar la imagen de España en el extranjero y la posición diplomática del régimen (Shaw, 1987: 44). No todas estas acusaciones especialmente las dos primeras - resultan fundamentadas, pero no cabe duda de que la identificación del Real Madrid con una imagen edulcorada del régimen le pasó factura cuando tanto el franquismo como el equipo de fútbol entraron en decadencia a mediados de la década de los sesenta.

\section{El lento declive y el ocaso del mito referencial madridista (1961-1978)}

La crisis no sólo tuvo una manifestación deportiva, sino financiera. Los éxitos en la Liga y en la Copa de Europa hicieron aumentar los ingresos por taquilla, pero obligaron a incrementar fuertemente el capítulo de fichajes, y plantear la ampliación del estadio e incluso la creación de una Ciudad Deportiva que fue inaugurada en 1963. Tras una poco lucida emisión de obligaciones en 1961, la deuda a largo plazo del Real Madrid alcanzó los 93,6 millones de pesetas. Para colmo, las primeras transmisiones de los encuentros por televisión produjeron grandes mermas de taquilla, y tras la costosa construcción del tercer anfiteatro el número de socios declinó paulatinamente, con la consiguiente reducción de los ingresos. En septiem- 
bre de 1963, el club estaba en virtual bancarrota. Los directivos barajaron la posibilidad de disolver las diferentes secciones deportivas, incluido el fútbol juvenil, hipotecar el estadio o clausurar y revender la Ciudad Deportiva para hacerla zona edificable (Saporta a Bernabéu [9-9-1963], en ARM, caja 324, carp. 1). Durante los años siguientes, el incremento progresivo del monto de las indemnizaciones por la retransmisión de partidos, la rentabilización de las instalaciones de la Ciudad Deportiva (sobre todo el Pabellón de Deportes inaugurado en 1966) y el contrato publicitario suscrito con la compañía eléctrica Philips dieron un respiro al Club, que con su victoria en la Copa de Europa de 1966 pudo mantener por un tiempo su "cachet" internacional. Aunque la cantera permitió una renovación de la esperanza de éxitos, las dificultades para reforzar el equipo con jugadores extranjeros de relieve limitaron las posibilidades del Madrid en la Copa de Europa. A inicios de los años setenta, la deriva defensiva del fútbol español (que fue también la tónica general en Europa) deslució el espectáculo y redujo de nuevo la asistencia de público a los partidos. Como consagración de su dominio del espacio simbólico de la España central (con toda su carga semántica a escala regional, representada en la franja morada del escudo madridista) el 21 de julio de 1972 el Real Madrid patrocinó la creación del Castilla como equipo filial procedente de la Agrupación Deportiva Plus Ultra, que había nacido el 16 de diciembre de 1930. La indumentaria escogida fue también de color morado.

La etapa del tardofranquismo y los primeros pasos de la transición hacia la democracia fueron el contexto político donde estalló la crisis de la entidad blanca: en la primavera de 1973, el club se vio envuelto en la gran polémica urbanística, cuando trató de recalificar los terrenos donde estaba situado el estadio de Chamartín para construir un gran rascacielos. El proyecto urbanístico, que en un principio contó con las simpatías de Franco, se frustró por la oposición frontal del Ayuntamiento de Madrid, de la Presidencia del Gobierno y de importantes poderes fácticos (García Candau, 1980: 107-109 y Martín Semprún, 1994: 123-132). En pleno declive físico, Bernabéu hubo de soportar los años más duros de su prolongado mandato al frente del Real Madrid. Poco antes de la muerte de Franco, los clubes y la opinión pública habían comenzado a cuestionar la gestión autoritaria de las estructuras deportivas, y dirigieron preferentemente su frustración contra el todopoderoso Real Madrid, acusado sin tregua de ser el "equipo del régimen", símbolo de un modo trasnochado de entender el nacionalismo español como un banderín de enganche para la pervivencia de la dictadura. Pero la propia entidad afrontaba un delicado futuro: tras el fiasco del proyecto de la "Torre Blanca", el Real Madrid emprendió a inicios de 1974 una profunda renovación del cuerpo técnico, y en marzo de 1976 confirmó el declive de su influencia europea al ser sancionado por la UEFA tras un incidente violento producido durante el partido semifinal de la Copa de Europa frente al Bayern de Munich. 


\section{Conclusión: el Real Madrid, ¿equipo de España?}

Fallecido el patriarca dos años y medio después del general Franco (con cuya gestión política algunos no dudaron en establecer inquietantes paralelismos en estilo y longevidad), el "delfín" Saporta trató de patronear una "transición" controlada, aunque no dudó en advertir que "solamente soy el Carrero Blanco de Bernabéu. El Príncipe de España debe ser otro" (García Candau, 1980: 99). Durante la presidencia continuista de Luis de Carlos (1978-85) se agudizó la crisis deportiva y se retrasó el necesario remozamiento de las estructuras de gestión del club. El final de la Dictadura y el establecimiento de un régimen democrático implicaron la plena normalización de las relaciones diplomáticas de España. Ya no era necesario recurrir a un club deportivo para obtener reconocimiento exterior. Los desplazamientos del equipo pudieron efectuarse sin ninguna cortapisa, y la cooperación del aparato diplomático ya sólo tenía sentido como muestra de cortesía. Para ese entonces, la trayectoria del Real Madrid había cristalizado en una imagen de marca que estaba por encima de los avatares de la política, e incluso del eclipse deportivo que sufrió el equipo en las competiciones internacionales hasta fines de los años noventa. A lo largo de su trayectoria centenaria, el Real Madrid había sabido mantener una actitud respetuosa y considerada hacia los poderes constituidos que sucesivamente han dirigido los destinos del país. Como declaraba rotundo Raimundo Saporta en los años ochenta:

"El Real Madrid es y ha sido político. Ha sido siempre tan poderoso por estar al servicio de la columna vertebral del Estado. Cuando se fundó en 1902 respetaba a Alfonso XIII, en el 31 a la república, en el 39 al generalísimo, y ahora respeta a Su Majestad Juan Carlos. Porque es un Club disciplinado y acata con lealtad a la institución que dirige la nación" (cit. por Shaw, 1987: 13 y 61).

En la administración del club ha prevalecido siempre una actitud de franca colaboración institucional y e incluso de amistad personal, con los líderes políticos, pero se ha mantenido el convencimiento de que, como institución deportiva, el Madrid no debía inmiscuirse en banderías partidistas, ni tampoco permitir intromisiones de fuerzas políticas en la marcha del club. En consonancia con estos criterios, las Juntas Directivas del Madrid siempre supieron permanecer alejadas de adhesiones inquebrantables, y, por supuesto, también de cualquier forma de oposición más o menos velada. Como hemos visto, durante el franquismo consiguieron en buena medida soslayar las injerencias o las interferencias políticas, en una época con predominio de tendencias totalitarias.

A diferencia de lo que señalan sus críticos, el Real Madrid fue y sigue siendo una sociedad deportiva de composición social e ideológica muy plural, con una buena disposición para las relaciones públicas, pero con un comportamiento muy circunspecto con el mundo de la política. Una actitud pretendidamente neutral en tanto que "apolítica" que, paradójicamente, le ha convertido en uno de los grandes símbolos y portaestandartes del nacionalismo español más banal y no comprometido ideológicamente. Pero con la libertad de expresión política en el deporte que se 
ha manifestado desde la transición, la impronta claramente nacionalista y reivindicativa que fueron asumiendo clubes como el F.C. Barcelona, Athletic de Bilbao o Real Sociedad (que consiguieron éxitos deportivos que rompieron con la hegemonía nacional e internacional del Madrid), condujo a un sector del madridismo a asumir un nacionalismo español en ocasiones reactivo y beligerante, con algunos toques de fascismo internacional, como muestra la simbología y las acciones performativas del grupo Ultras Sur. Aunque la exhibición ocasional de símbolos nacionales (banderas bicolores y bufandas con el toro de Osborne, capotes de torear...) se sigue dando en los encuentros y en las celebraciones que tienen lugar en un espacio capitalino tan representativo como la Plaza de Cibeles, el papel del Real Madrid como "equipo de España" y como principal referente deportivo del nacionalismo banal ha quedado muy disminuido con los recientes éxitos continentales y mundiales de la selección española, cuya identidad notoria y su composición plural la hace más creíble como vehículo de exhibición de un nacionalismo español inclusivo de regiones y grupos sociales (por ejemplo, la emigración extranjera) hasta ahora poco proclives a este tipo de compromisos identitarios. El club va camino de convertirse en un buen ejemplo de cómo el deporte profesionalizado logra compatibilizar identidades primordiales de orden local o nacional con identidades de naturaleza transnacional, no sólo por el origen plural de sus jugadores (que en las victorias no dudan en exhibir sus símbolos de origen), sino porque su transformación en fenómeno global le convierte a ojos de sus seguidores de todo el mundo en una marca cuya imagen trasciende las fronteras convencionalmente establecidas. 


\section{Abreviaturas}

AMAE Archivo del Ministerio de Asuntos Exteriores (Madrid).

ARM Archivo del Real Madrid C. de F.

BIRM Boletín Informativo del Real Madrid C. de F.

DND Delegación Nacional de Deportes.

FIFA Federación Internacional de Fútbol Asociación

RFEF Real Federación Española de Fútbol.

UEFA Unión de Federaciones de Fútbol Europeas

\section{Bibliografía}

Armstrong, Gary y Richard Giulianotti. 1999. Football Cultures and Identities, Londres: MacMillan Press Ltd.

Bahamonde Magro, Ángel. 2002. El Real Madrid en la historia de España, Madrid: Taurus.

Billig, Michel. 1995. Banal Nationalism, Londres: Sage.

Bromberger, Christian. 1998. Football, la bagatelle la plus sérieuse du monde, París: Bayard Éditions.

Burns Marañón, Jimmy. 1999. El Barça, la pasión de un pueblo, Barcelona: Anagrama.

Di Stéfano, Alfredo. 2000. Gracias, vieja, Madrid: Aguilar.

Escandell Bonet, Bartolomé; Eduardo González Calleja y Francisco Villacorta Baños (coords.) (2002. Historia del Real Madrid, 1902-2002. La entidad, los socios, el madridismo, Madrid: Everest/Fundación Real Madrid, 2 vols.

Fernández Santander, Carlos. 1990. El fútbol durante la Guerra Civil y el franquismo, Madrid: San Martín.

García Candau, Julián. 1980. El fútbol, sin ley, Madrid: Penthalon.

García Candau, Julián. 1996. Madrid-Barça: historia de un desamor, Madrid: El País.

García Candau, Julián. 2002. Bernabéu, el presidente, Madrid: Espasa.

García Ferrando, Manuel; Nuria Puig Barata y Francisco Lagardera Otero (comps.) (1998), Sociología del deporte, Madrid: Alianza.

González Calleja, Eduardo y Rey Reguillo, Fernando del. 1995. La defensa armada contra la revolución, Madrid: CSIC.

González, Luis Miguel. 1977. Grandes clubs españoles. Historia del Real Madrid, 1902-1977, Madrid: Coleccionables de As Color.

González, Luis Miguel. 2002. Real Madrid, cien años de leyenda, 1902-2002, Madrid: Everest/Fundación Real Madrid.

Martialay, Félix. 1996. La implantación del profesionalismo en el fútbol español y el nacimiento accidentado del torneo de liga, Madrid: RFEF.

Martialay, Félix y Salazar, Bernardo de. 1997. Las grandes mentiras del fútbol español, Madrid: Fuerza Nueva. 
Martín Semprún, Jaime. 1994. Santiago Bernabéu: "la causa”. Biografia, Barcelona: Ediciones B.

Melcón Bartolomé, Ramón. 1950. Historia del Real Madrid C. de F., Madrid: Eds. Deportivas.

Melcón, Bartolomé y Stratton Smith (eds.). 1961. The Real Madrid Book of Football (with contributions by Alfredo Di Stefano, Ferenc Puskas, Francisco Gento, Jose Santamaria, José Zarraga, Rogelio Dominguez, Luis del Sol, Santiago Bernabéu, Raimundo Saporta and others), Londres: Souvenir Press.

Mosse, George L. 1975. La nazionalizzazione delle masse. Simbolismo politico e movimenti di massa in Germania (1815-1933), Bolonia: Il Mulino.

"Partisans" (seud. colectivo). 1978. Deporte, cultura y represión, Barcelona, Gustavo Gili.

Quiroga Fernández de Soto, Alejandro. 2004. “'Los apóstoles de la Patria'. El Ejército como instrumento de nacionalización de masas durante al Dictadura de Primo de Rivera", Mélanges de la Casa de Velázquez, 34 (1): 243-272.

[El] Real Madrid, campeón de Europa, Madrid: Prensa Española, 1996.

Rosón, Manuel. 1940. 40 años de historia del Madrid F.C. (1900-1940), por un veterano, Madrid: Eds. Alonso.

Sabartés, Jaime S. 1982. Barça, cara i creu. El F.C. Barcelona sota el franquisme (1939-1975), Barcelona: Laia.

Shaw, Duncan. 1987. Fútbol y franquismo, Madrid: Alianza.

Vinnai, Gerhard. 1970. Fußball als Ideologie, Frankfurt: Europäische Verlaganstalt, 1970. 